\title{
Commentary: A tale of the left ventricle
}

\author{
Kristopher B. Deatrick, MD, and Sunjay Kaushal, MD, PhD
}

From the Division of Cardiac Surgery, University of Maryland School of Medicine, Baltimore, Md Disclosures: Authors have nothing to disclose with regard to commercial support.

Received for publication April 10, 2019; accepted for publication April 11, 2019.

Address for reprints: Sunjay Kaushal, MD, PhD, Division of Cardiac Surgery, University of Maryland School of

Medicine, 110 S Paca St, 7th Floor, Baltimore, MD 21201 (E-mail: skaushal@smail.umaryland.edu).

J Thorac Cardiovasc Surg 2019;158:518-9

$0022-5223 / \$ 36.00$

Copyright $(2019$ by The American Association for Thoracic Surgery

https://doi.org/10.1016/j.jtcvs.2019.04.051

The historical outcomes of the Ross or Ross-Konno operation in centers of excellence remain outstanding, and it remains the criterion standard surgical repair for infants, children, and adolescents with aortic stenosis or regurgitation or with left ventricular outflow tract obstruction. ${ }^{1-3}$ Despite the inherent advantages of the Ross or RossKonno operation, including the potential for somatic growth, most long-term outcome studies have centered on the deterioration of the aortic autograft or pulmonary homograft. Another potential long-term complication yet to be determined is the growing concern for electromagnetic dyssynchrony, given the high prevalence of bundle branch block and prolonged QRS duration in patients undergoing Ross and Ross-Konno operations. ${ }^{4}$ Once electromagnetic dyssynchrony is identified, cardiac resynchronization therapy readily treats ventricular dyssynchrony, with positive remodeling of the left ventricle, which may affect longterm outcomes.

In this issue of Journal, Schäfer and colleagues ${ }^{5}$ present their experience to evaluate and compare the extent of electrical and mechanical dyssynchrony with cardiac magnetic resonance imaging after Ross and Ross-Konno operations. In their study, they determined that patients undergoing both the Ross and Ross-Konno operations had normal biventricular functional status but reduced left ventricle longitudinal strain. In addition, both groups demonstrated increased right-left inter-ventricular dyssynchrony relative to the control group, but only the Ross-Konno group had increased septal left intraventricular dyssynchrony. More importantly, the global left ventricular intramechanical dyssynchrony strongly correlated with QRS duration. The significance of the relationship between these findings and meaningful clinical outcomes need further evaluation; however, patients who have undergone either the Ross or RossKonno operation may have chronic increased afterload, independent of the consequences of the left ventricular function or the autograft and pulmonary graft function.

As a pilot study, this thoughtful evaluation of ventricular function by Schäfer and colleagues ${ }^{5}$ raises critical and interesting questions. Although there are changes in left ventricular strain and function, in addition to dyssynchrony, in

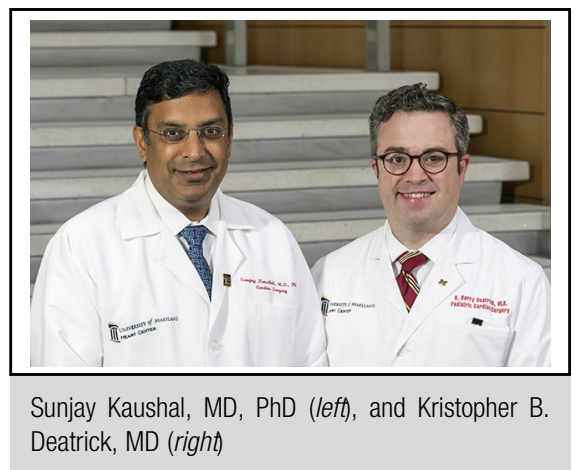

Central Message

This study adds to the understanding of the complex interplay between cardiac electrical physiology, myocardial coordination and function in patients undergoing Ross and RossKonno operations.

See Article page 509

patients who have undergone Ross and Ross-Konno operations relative to control patients, the use of normal, healthy patients as a control group leads to the question of whether these findings are indicators of the primary pathology. In other words, negative left ventricular remodeling may still be present long after the relief of left ventricular outflow obstruction or the correction of aortic stenosis or regurgitation, even after surgical intervention. In any circumstance, for young patients, particularly neonates and infants, there are currently no other suitable surgical options. Although electrical dyssynchrony has been shown to lead to mechanical dyssynchrony and adversely affect function in adults, it is uncertain what the degree of reduced left ventricular strain, as measured by magnetic resonance imaging, will portend for these patients in the future. ${ }^{6}$ The finding that this metric of left ventricular strain is more predictive of mortality than left ventricular ejection fraction for adult patients with acute decompensated heart failure, however, suggests that these patients may have a greater risk of reduced long-term outcomes. ${ }^{7}$ We must be cautious, however, in extrapolating data from a different surgical population group of adults with a fundamentally different pathophysiology for predictions related to patients who have undergone Ross and Ross-Konno operations. Finally, although it is a single-institution, retrospective experience, this study raises the additional question of when to intervene when left ventricular global longitudinal strain is present in these patients. 
This study of Schäfer and colleagues ${ }^{5}$ adds to the understanding of the complex interplay of cardiac electrical physiology, myocardial coordination, and function in patients who have undergone Ross and Ross-Konno operations. The next step will determine when an intervention with cardiac resynchronization therapy will need to occur according to the degree of left ventricular strain abnormalities present on magnetic resonance imaging. Regardless, studying these patients who have undergone Ross and Ross-Konno operations for continued abnormalities in left ventricular performance will be critical for their long-term outcomes.

\section{References}

1. Nelson JS, Pasquali SK, Pratt CN, Yu S, Donohue JE, Loccoh E, et al. Long-term survival and reintervention after the Ross procedure across the pediatric age spectrum. Ann Thorac Surg. 2015;99:2086-94; discussion 2094-5.

2. Brown JW, Ruzmetov M, Vijay P, Rodefeld MD, Turrentine MW. The Ross-Konno procedure in children: outcomes, autograft and allograft function, and reoperations. Ann Thorac Surg. 2006;82:1301-6.

3. David TE, Ouzounian M, David CM, Lafreniere-Roula M, Manlhiot C. Late results of the Ross procedure. J Thorac Cardiovasc Surg. 2019;157:201-8.

4. Pasquali SK, Marino BS, Kaltman JR, Schissler AJ, Wernovsky G, Cohen MS, et al. Rhythm and conduction disturbances at midterm followup after the ross procedure in infants, children, and young adults. Ann Thorac Surg. 2008;85:2072-8.

5. Schäfer M, Browne LP, von Alvensleben JC, Mitchell MB, Morgan GJ, Ivy DD, et al. Ventricular interactions and electromechanical dyssynchrony after Ross and Ross-Konno operations. J Thorac Cardiovasc Surg. 2019;158: 509-17.

6. Nagueh SF. Mechanical dyssynchrony in congestive heart failure: diagnostic and therapeutic implications. J Am Coll Cardiol. 2008;51:18-22.

7. Park JJ, Park JB, Park JH, Cho GY. Global longitudinal strain to predict mortality in patients with acute heart failure. J Am Coll Cardiol. 2018;71:1947-57. 